\title{
Model-based long-term pricing in maritime container shipping
}

\author{
Jörn Schönberger ${ }^{1}$ \\ Published online: 26 May 2020 \\ (c) The Author(s) 2020
}

\begin{abstract}
This article reports the development and the assessment of a freight rate optimization approach based on mathematical modeling and optimization. It exploits the functional interdependency between the price of a (service) product and the quantity of the product using this price. Solving the proposed model enables a differentiated and shipper-specific rate determination accompanied by the allocation of the transport capacity provided by the carrier to different shippers. This bilateral pricing between carrier and shippers considers market-based reference rates typically available in the maritime container shipping industry. Herewith, we integrate market-based pricing with demand-based pricing. We validate the proposed model in computational experiments for an artificial pricing scenario. An analysis of the achieved results demonstrates that missing overcapacities will lead to reduced revenues if spot market prices are too low.
\end{abstract}

\section{Introduction}

The transport sector is a major global contributor to the overall emission of greenhouse gases (GHG), of a bunch of other harmful substances as well as of particles. This sector is responsible for $\approx 24 \%$ of global $\mathrm{CO}_{2}$ emissions from fuel combustions (IEA 2019). Reports state the allocation of $14 \%$ of the GHG for this sector. A further increase by up to $50 \%$ until 2050 was projected (Edenhofer et al. 2014). This development is unique compared to the other significant industries, which often have already realized substantial reductions of harmful emissions in the recent past. Furthermore, other sectors have reliable agreements on how to reduce their emissions in the next decades.

Maritime shipping emitted only $2.1 \%$ of global GHG in 2012 (IMO 2015), but studies forecast a significant increase of additional GHG emissions until 2050. Besides GHG-emissions, the maritime shipping sector is responsible for a variety of other negative impacts on plant and animal life due to conscious as well as accidental air and water pollution. A comprehensive survey about the vast and diversified implications of maritime shipping to the environment gives (Walker et al. 2019).

Jörn Schönberger

joern.schoenberger@tu-dresden.de

1 Faculty of Transportation and Traffic Sciences, Chair of Transport Services and Logistics, Technische Universität Dresden, 01069 Dresden, Germany
A GHG reduction scheme dedicated to the maritime shipping sector was agreed by the IMO in 2018 (IMO 2018). The IMO postulates a mix of methods directed to adopt the design and construction of vessels, the partial replacement of fossil fuel combustion as well as the adaptation of operations. A recent study (European Commission 2019) also emphasized the latter aspect. Maritime container shipping is the backbone of worldwide transportation and trade covering between 80 and $90 \%$ (in weight) of the sector's activities (ECSA 2017). An over-proportional growth of GHG, as well as $\mathrm{CO} 2$ emissions, is expected, which is mainly caused by a forecasted increase in transport performance (Sames and Köpke 2012). This observation induces an expansion of the global fleet size and the total transport capacity. Countermeasures are necessary to establish additional concepts to reduce the total emission from the global maritime container shipping sector.

Operational changes have the potential to become effective quite soon compared to the retrofit of vessel designs or the development of new engine technologies. Therefore, short-term business behavior changes seem to be promising to contribute significantly to the targeted GHG reductions projected in (IMO 2018), which have then a realistic chance of realization until 2030. Pricing is one of the operationally working adjust screws whose usage can contribute to influencing how shippers use available vessel capacity. Even the most recently proposed vessel designs require a fully loaded journey to realize the proposed increase in environmental efficiency to the most substantial possible extent. In this article, we are going to evaluate within computational simulation experiments if a change in pricing has the poten- 
tial to increase the degree of vessel capacity utilization. We propose to apply mathematical programming techniques to set individual and shipper-specific rates depending on the required capacity instead of demand-unrelated rates. In line with model-based pricing approaches found (among others) in the electric power supply business (Doostizadeh and Ghasemi 2012) or for road tolling (Fu and Kulkani 2013), the idea is to actively set prices to control the demand of using a scarce resource. The application of a model-based pricing scheme enables a stable resource utilization and avoids a peak-demand capacity dimensioning.

The remainder of this article starts with a discussion of the suitability of pricing as a tool to achieve more sustainability in shipping operations. Sect. 3 addresses the challenge of coordinating individually fixed rates with marketbased (reference) prices. Sect. 4 provides a brief overview of papers that address the optimization of freight rates. The fifth section contains the presentation of a mathematical optimization model for the freight rate specification. Sect. 6 provides insights into computational experiments.

\section{Sustainability and pricing in the container shipping industry}

The container shipping industry has been a customer-oriented market for several decades now. Market or reference rates like the Shanghai Containerized Freight Index are a distinguishing ingredient of maritime container transportation. Such a reference rate represents the market situation, and its variation gives hints to the availability of transportation capacity. Due to the recent market power of shippers (the customers of the carriers/vessel operators), the reference rates mentioned above contradict individual pricing negotiations between carrier and shipper. In periods with low reference rates, the individually agreed prices will also be moderate, but in periods with high reference rates, individual pricing negotiations become possible. This mechanism results in extended overbooking and blocking activities during low pricing periods, which endangers the efficiency of the associated terminal and transshipment processes. The sustainability of processes involving maritime container transportation is negatively affected by overbooking and blocking since, often, booked vessel capacity remains finally unused.

The protection of maritime transport service reliability is essential. Preventing adverse side effects and ensuring the economic survival of the carriers are needed. For all of this, it is necessary to try to balance the market power back towards a more equalized setup, i.e., carriers and shippers become similarly powered partners. In such a complicated market setup, it is even more challenging to establish the measures mentioned above towards increased sustainabil- ity of maritime container transport. Here, the two points of attack are essential. First, we need to increase the capacity utilization of the deployed fleet to exploit the maximal energy efficiency of the used vessels. Second, keeping rates stable over a longer time means to reduce negative impacts resulting from rates varying with high frequency.

In conclusion, both ecological, as well as economic reasons, require the initiation of actions to lift the capacity utilization of container vessels. A pure capacity reduction is inappropriate since demand varies over time (i.e., due to seasonal demand). Furthermore, a "buy ahead" of slots in periods of low freight rates is promoted to ensure revenue income even in times of higher prices and reduced market demand.

The two earlier mentioned issues address the simultaneous capacity utilization rate increase and the increase of revenues of the vessel operators as well as the identification of stable long-term rates. It is necessary to develop an operational method, which contributes to the short-term capacity utilization increase as well as the protection of the revenues.

Although demand-oriented pricing is already in use in several applications (Dai et al. 2014), its exploitation in the maritime container shipping industry seems to be undocumented. This article addresses the conceptualization and specification of a mathematical model that calculates "optimal" prices. Here, "optimal" refers to both the maximization of revenues of the vessel operators as well as to the capacity utilization optimization of a specific vessel service. We limit our research to a selected trip servicing a given origin-to-destination relation. The particular challenge of demand-oriented pricing in the maritime container transportation market addresses the appropriate consideration of the reference rates. Due to their market power, shippers are standing on the reference prices in periods of low reference rates. However, they will accept longer-term fixed rates in periods of high reference rates.

In this context, we try to find answers to the following research questions:

1. How can we derive stable rates that maximize the carrier's revenues but consider that lower reference rates will "overrule" any fixed rates?

2. What are impacts on capacity utilization and revenues of longer-term rates agreed between a carrier and individual shippers, but which the shippers temporarily overrule?

We use the following methodological approach. First, we develop an explicit mathematical pricing model for the rate decision problem of the carrier. Next, we apply this model in a simulated environment in which we mimic the selling of container vessel capacity (slots) to shippers. We do this under different reference rate evolutions. To derive answers 
to the stated research questions, we evaluate and analyze the observed quantitative results.

Specifying the pricing model for the maritime container shipping sector requires a methodological innovation. Existing mathematical pricing models do not consider this issue since they assume a quasi-monopolistic carrier-oriented market. In this paper, we propose a pricing approach that can recognize the reference rates during the identification of shipper-specific prices per TEU.

In line with the explanations given in the previous paragraphs, this paper presents as a first step towards a comprehensive scientific analysis and investigation of decision support for rate determination in the container transportation business. The methodological foundation of the here reported research comprises the mathematical modeling of the underlying decision situation. More concretely, we use mixed-integer linear programming to formally represent the freight rate planning problem of a container vessel carrier. Demand-based pricing concepts from revenue management are combined with market-based pricing by reference rates. This mixed-approach enables the optimization of the prices.

\section{Coordination of mutually agreed demand- oriented rates and market rates in transportation}

In the transportation industry, freight rates describe the charges to be paid by a shipper to a carrier as compensation for the carrier's transport service. The freight rate determination might be regulated by laws or similar rules (like in the commuter sector where the public government works as contracting authority) or left to the market where carriers and shippers mutually agree on rates. Concerning the power to enforce the own rate proposals, we can distinguish two different scenarios. In a shipper-controlled market, shippers can implement their rate proposals. However, in a carrier-controlled market, carriers have the power to set the rates. In the shipper-controlled market, the same price applies to all selling interactions between an arbitrary shipper and the carrier. Therefore, the commonly accepted and used rate is called a market rate or a reference rate. Vessel operators tend to provide too much capacity in the shipper/ carrier market to be sure to serve any request. In contrast, in a carrier-controlled market, transport capacity is scarce, and individual rates can be agreed between a carrier and a shipper since no prevailing market rate exists. Instead, the particular demand expressed by a shipper drives the determination of the applied price.

The container shipping industry is a shipper-oriented market for several decades now. It is necessary to try to balance the market power back towards a more equalized setup, i.e., carriers and shippers become similarly powered partners. In such a situation, freight rates might be the outcome of a "mixture" of market rates as well as individual rates depending on available capacities and demand in the market for selected regions or on selected relations/routes.

Pricing in competitive situations is complicated and requires the explicit consideration of both involved parties, which are the seller (in our case, the "carrier") and the buyer (in our case, a "shipper"). In a typical setup with bargained freight charges, few sellers interact with a considerable set of individually behaving buyers. The determination of the freight rates requires taking into account decision making form both parties. Taking the perspective of the seller (the carrier) requires considering the reaction/response of each buyer besides available capacities. If there are hundreds or even more individually reacting buyers, it is impossible to take into account their reactions. Instead, probability-based evaluations of a seller decision by the complete set of buyers are needed, which are formalized by so-called customerchoice models (Temme 2007). In the last years, so-called choice-based optimization approaches (Vulcano et al. 2010) have been successfully conducted, mainly in transportation scenarios (Dai et al. 2014).

In choice-based optimization, it is essential to understand how the seller (who tries to set the prices) can set reasonable price proposals to be evaluated in choice-models. In this paper, we address this currently hypothetic situation of balanced market power intending to provide rate-determining computer-based decision support tools. The reason for this specific research is twofold. First, we want to determine the reference results. Second, it is necessary to get an idea of how a carrier can calculate rates considering available capacity and willingness-to-pay of shippers as well as potentially existing reference rates.

Different approaches are available for pricing. Costbased pricing relies mainly on service production costs. Here, a profit margin amount enlarges the observed cost amounts. The profit margin represents the surplus of the service provider. Cost-based pricing is the preferred strategy in a carrier-oriented market. In the transport business, costbased pricing applies for full truckloads in the road haulage industry and the whole charter business in maritime as well as air transport (Schubert 2013). Cost-based pricing in the less-than-complete load sector is inappropriate since the extent of fixed costs for the vehicle or vessel deployment is quite high compared to the marginal variable costs for moving an additional load unit. Therefore, the distribution of the sum of fixed costs to different customer requests is hardly possible.

Two other base alternatives for pricing are available: First, prices equal reference rates observed in the corresponding market ("market-based pricing"). Second, it is possible to determine a rate mainly based on the willing- 
ness-to-pay of the prospective customers ("demand-based pricing").

Some markets for transport services provide reference rates that the seller can exploit to set the prices. The maritime container vessel service market maintains several of these reference rates for several routes and regions, for example, the Shanghai Containerized Freight Index, which serves as a reference rate for a TEU outbound from Shanghai. Pricing based on a reference rate represents a marketbased pricing scheme.

In the context of the second alternative, the price of a transport service influences the number of moved units. A demand-price-function (DPF) formalizes this functional interrelationship. A DPF describes the demand-price-relationship between a carrier and a shipper (for different service levels). A carrier exploits the DPF and looks for a quantity reserved for the shipper that maximizes its gained revenue sum, which is the product of the quantity $q^{o p t}$ multiplied with the corresponding rate $\operatorname{DPF}\left(q^{\text {opt }}\right)$. Therefore, we understand the DPF as a representative for a demand-based freight rate determination scheme. However, the existence of a market rate disrupts the exploitation of a DPF.

At first glance, it seems to be reasonable for the container shipping industry to focus on the deployment of a pure market-based pricing scheme exploiting only the available reference rates. At second glance, market prices vary, and exogenous impacts exist. To hedge against rate variations, both the carriers as well as the shippers would like to agree on longer-lasting rates ("fixed rates", FR). For a carrier, a fixed rate forms the foundation of the financial contribution to the provision of the necessary transport capacities since they stabilize the revenue. Besides, shippers realize high planning reliability and can, therefore, reduce the risk of their expenditures in operations compared to the spot market. Note that a reference rate can represent a spot market rate ("short term rate", SR).

Depending on the actual market position, shippers will enforce the application of short-term rates even after a price agreement signed in a contract for a certain pricing period ("overruling"). In case that a carrier wants to determine a fixed rate that covers several consecutive pricing periods, the expected SRs have to be considered to avoid unexpectedly reduced revenues. This consideration requires the integration of demand-based pricing with market-based pricing in a simultaneous rate planning approach. The remainder of this article addresses the development and evaluation of a mathematical optimization model for the a priori determination of longer-term freight rates under consideration of varying market rates exploiting DPFs of the available shippers. The proposed approach realizes the integration of a market component into the demand-based freight rate determination.

\section{Literature on model-based pricing in the transport sector}

Price optimization is the subject of pricing, which is a part of the management discipline revenue management (RM). RM aims at finding the best prices from the carrier's perspective following the idea of demand-based pricing to realize the absorption of consumer surplus. RM-techniques exploit the differences in the willingness-to-pay associated with different customer groups to maximize the vendor's income. Therefore, RM does not postulate the market-based pricing of products since it exploits the individual price sensitivity of market contributors. Besides the determination of prices, RM provides additional tools to sell different combinations of a product associated with a customer-groupspecific price/rate to different customer groups, which is called capacity control. RM tries to filter incoming requests so that limited resource capacity is assigned to the most profitable requests even if their time of appearance is uncertain.

In case that the DPFs for several customers compete for one or more products using a scarce resource, then the simultaneous determination of revenue-maximal sales prices is called prize discrimination (Kimes 2017). Sales prizes assigned to the different customers refer to capacities. Therefore, the available capacity restricts the rate variation. The maximal demand from the market or the total sum of demand from different market segments may restrict the variation of rates. In contrast, if there is no capacity scarceness like in an overcapacity situation, then prizes can be set independently from the available capacity. Furthermore, an increase in sold quantities compensates price decreases. The same is true if the demand from the market is quite high (Bertsimas and Popescu 2003).

Quantitative approaches, which investigate the sales part in the maritime container shipping industry, address capacity control techniques. In this context, the discussion of slot allocation problems is in focus. Here, vessel operators are searching for transport capacity on existing services to collected maximal amounts of revenues. They want to assign the highest accepted price to every customer (Wang et al. 2015a).

Only very few research reports address the identification of the "best" freight rate (here for a TEU). The article (Jugovic et al. 2015) investigates influencing factors for the freight rate determination in the maritime industry. The authors of (Yin and Kim 2012) report the freight rate determination in the sense of a prize discrimination. They determine a base freight rate and decide about discounts to attract more demand to maximize the revenue sum collected from different customers. However, the authors do not exploit DPFs. 
The work of Wang et al. (2015b) reports the determination of freight rates on the tactical as well as on the operational level. Demand coded in an OD-matric structure is distributed over services in a given network to maximize expected revenues. On the tactical perspective, they integrate capacity allocations and associated freight rates (per TEU) using a proportional DPF. However, the authors do not apply these freight rates in the operational context. For that, they deploy a weekly-published reference rate.

\section{Decision problem of coordinating short- term and long-term freight rates}

\subsection{The decision task}

We consider a carrier, i.e., a vessel operator that offers a transport service on a particular relation from an origin port to a destination port over several periods $p \in P$. The provided capacity measured in TEU in period $p$ equals $C A P_{p}$. A midterm sales planning aims at selling this capacity to the shippers. We collect all shippers in the set $C$. The carrier aims to identify a rate (per TEU) $f_{i}$ for each shipper $i$ that is fixed for all periods so that the total sum of revenues gained by the carrier over all periods and from all shippers is maximal. Each shipper can overrule $f_{i}$ in a period $p$ when the short-term rate $S R_{p}$ in period $p$ beats the long-term rate, i.e., $S R_{p}<f_{i}$.

As long as the DPF applies, the carrier controls the realized fixed term rate for a shipper. The carrier adjusts the TEU allocated for this shipper. In a period in which the market rate beats the long-term rate, the DPF does not work, and therefore, the carrier loses control about the demand capacity. For this reason, a carrier (assuming a limited total transport capacity) may become unable to provide the demanded capacity. Consequently, transport quantity gets lost, and the increase of the moved TEU cannot compensate for the associated revenue loss per TEU.

\subsection{Mathematical pricing model}

Subsequently, we present a mixed-integer linear program of the described rate determination problem. The model follows the idea to determine the possible period- and shipperspecific revenue sum for both the fixed rate $f_{i}$ as well as the short-term (market) rate $S R_{p}$. The model enables the comparison of both revenue sums and identifies the rate with the higher revenue as the applicable rate for the shipper in the considered period.

\subsubsection{Determination and comparison of revenues for both} rates

$\sum_{c \in C} \sum_{p \in P} \operatorname{contrib}_{c p}^{S R}+\sum_{c \in C} \sum_{p \in P} \operatorname{contrib}_{c p}^{F R} \rightarrow \max$

$f_{c}-S R_{p} \leq \mathrm{SEL}_{c p}^{S R} \cdot M ; \forall c \in C, p \in P$

$S R_{p}-f_{c} \leq \mathrm{SEL}_{c p}^{F R} \cdot M ; \forall c \in C, p \in P$

$\mathrm{SEL}_{c p}^{S R}+\mathrm{SEL}_{c p}^{F R}=1 ; \forall c \in C, p \in P$

$\operatorname{contrib}_{c p}^{S R}=\mathrm{REV}_{c p}^{S R}-\mathrm{DIFF}_{c p}^{S R} ; \forall c \in C, p \in P$

$\operatorname{DIFF}_{c p}^{S R} \leq\left(1-\mathrm{SEL}_{c p}^{S R}\right) \cdot M ; \forall c \in C, p \in P$

$\operatorname{contrib}_{c p}^{S R} \leq \mathrm{SEL}_{c p}^{S R} \cdot M ; \forall c \in C, p \in P$

$\operatorname{contrib}_{c p}^{F R}=\mathrm{REV}_{c p}^{F R}-\mathrm{DIFF}_{c p}^{F R} ; \forall c \in C, p \in P$

$\operatorname{DIFF}_{c p}^{F R} \leq\left(1-\mathrm{SEL}_{c p}^{F R}\right) \cdot M ; \forall c \in C, p \in P$

$\operatorname{contrib}_{c p}^{F R} \leq \mathrm{SEL}_{c p}^{F R} \cdot M ; \forall c \in C, p \in P$

We declare two families of non-negative continuous decision variables. First, contrib ${ }_{c p}^{S R}$ represents the gained revenue sum collected from shipper $c$ in period $p$ in case that the market rate applies in period $p$. Simultaneously, we define contrib ${ }_{c p}^{F R}$ as the sum of collected revenues from shipper $c$ in period $p$ in case that the carrier applies the long term rate. The sum of all revenues from both rates for all periods collected from all carriers should be as large as possible (1).

In case that the binary decision variable $\mathrm{SEL}_{c p} S R$ equals " 1 " then the spot-market rate $S R_{p}$ applies for shipper $c$ in period $p$ since this market rate is less than the agreed longterm rate $f_{c}(2)$. Analogously, the corresponding indicator variable $\mathrm{SEL}_{c p}^{F R}$ is enforced to " 1 " if the contracted rate is less than the spot market rate (3). Precisely one of the two cases above takes place in every period and for every shipper (4).

We distinguish realized revenues stored in $\operatorname{contrib}_{c p} S R$ as well as potential revenues stored in $\operatorname{REV}_{c p} S R$. The decision variable DIFF ${ }_{c p}^{S R}$ stores the difference between the two values (5). As soon as the spot market rate applies for shipper $c$ in period $p$, this difference equals " 0 " (6), but in all other cases the actual revenue gains from the spot market rate fulfill the property contrib ${ }_{c p}^{S R}=0$ (7). In the same way, revenues associated with the fixed rate are handled (8)-(10).

\subsubsection{Period- as well as shipper-specific capacity allocations}

$q_{c p}^{F R}=\sum_{k \in K} k \cdot Y Y_{\mathrm{kcp}}^{F R} ; \forall c \in C, p \in P$

$\sum_{k \in K} Y Y_{\mathrm{kcp}}^{F R}=1 ; \forall c \in C, p \in P$

$q_{c p}^{S R}=\sum_{k \in K} k \cdot Y Y_{\mathrm{kcp}}^{S R} ; \forall c \in C, p \in P$ 


$$
\begin{aligned}
& Z Z_{c p}^{S R}+\sum_{k \in K} Y Y_{\mathrm{kcp}}^{S R}=1 ; \forall c \in C, p \in P \\
& q_{c p}^{S R}=q_{c p}^{S R, F F}+q_{c p}^{S R, N F} ; \forall c \in C, p \in P \\
& q_{c p}^{S R, F F} \leq\left(1-Z Z_{c p}^{S R}\right) \cdot M ; \forall c \in C, p \in P \\
& q_{c p}^{S R, F F}=\sum_{k \in K} k \cdot \mu_{\mathrm{kcp}}^{S R, F F} ; \forall c \in C, p \in P \\
& 1=\sum_{k \in K} \mu_{\mathrm{kcp}}^{S R, F F} ; \forall c \in C, p \in P
\end{aligned}
$$

Let $K$ denote the set of possible contingents (number of TEU) reserved for a customer. We assume that there is a customer-specific $D P F_{c}$ known that is period-invariant. It maps the number of TEU allocated for a shipper to the rate per TEU. If $k \in K$ represents the number of TEU, then the associated customer-specific rate is $D P F_{c}(k)$. If and only if we select contingent $k$ for shipper $c$ in period $p$ the binary decision variable $Y Y_{\mathrm{kcp}}^{F R}$ equals " 1 " and the decision variable $q_{c p}^{F R}$ stores the contingent $k$ (11). Exactly one contingent is selected for every shipper in each period (12). Similarly, we determine the contingent $q_{c p}^{S R}$ for the situation when the spot market rate applies in period $p$ for shipper $c$ (13). Either the associated rate (between 0 and the maximal demand) is determined, or it is that the spot-market rate exceeds the maximal willingness to pay of shipper $c$ in period $p$. In the later mentioned case, the indicator variable $Z Z_{c p}^{\mathrm{STR}}$ is set to " 1 " (14). In order to avoid allocating a TEU number larger than the available capacity, we split the determined contingent into two parts. The first part $q_{c p}^{S R, F F}$ represents the realizable fraction but the second part $q_{c p}^{S R, N F}$ cannot be served (15). In the case that the spot market rate exceeds the maximal willingness to pay of shipper $c$ in period $p$ the contingent 0 is allocated for this shipper in this period (16). In all other cases, we set the corresponding binary decision variables $\mu_{\mathrm{kcp}}^{S R, F F}$ appropriately (17)-(18).

\subsubsection{Demand-price-functions}

$$
\begin{aligned}
& \operatorname{rate}_{c p}^{S R}=Z Z_{c p}^{S R} \cdot S R_{p}+\sum_{k \in K} \mathrm{APF}_{c}(k) \cdot Y Y_{\mathrm{kcp}}^{S R} ; \\
& \forall c \in C, p \in P \\
& \operatorname{rate}_{c p}^{S R}=S R_{p} ; \forall c \in C, p \in P \\
& \operatorname{rate}_{c p}^{F R}=\sum_{k \in K} \mathrm{APF}_{c}(k) \cdot Y Y_{\mathrm{kcp}}^{F R} ; \forall c \in C, p \in P \\
& \operatorname{rate}_{c p}^{F R}=f_{c} ; \forall c \in C, p \in P \\
& \operatorname{REV}_{c p}^{S R}=\sum_{k \in K} S R_{p} \cdot k \cdot \mu_{\mathrm{kcp}}^{S R, F F} ; \forall c \in C, p \in P \\
& \operatorname{REV}_{c p}^{F R}=\sum_{k \in K} \mathrm{APF}_{c}(k) \cdot k \cdot Y Y_{\mathrm{kcp}}^{F R} ; \forall c \in C, p \in P
\end{aligned}
$$

We first calculate the spot market rate for each shipper in each period (19). It equals the given spot-market rate so that each shipper exploits the same spot-market rate (20).
Constraint (21) determines the shipper-specific but stable contracted rate (22). We use the given spot market rate as well as the fixed contracted rate for the calculation of the potential revenue sums $\operatorname{REV}_{c p}^{S R}(23)$ as well as $\operatorname{REV}_{c p}^{F \mathrm{R}}(24)$.

\subsubsection{Limitations of capacity and demand}

$q_{c p}^{S R, F F} \leq q_{c p}^{S R, \mathrm{eff}}+\left(1-\mathrm{SEL}_{c p}^{S R}\right) \cdot M ; \forall c \in C, p \in P$

$q_{c p}^{S R, \mathrm{eff}} \leq D_{c p}^{\max }+\left(1-\mathrm{SEL}_{c p}^{S R}\right) \cdot M ; \forall c \in C, p \in P$

$q_{c p}^{F R} \leq q_{c p}^{F R, \mathrm{eff}}+\left(1-\mathrm{SEL}_{c p}^{F R}\right) \cdot M ; \forall c \in C, p \in P$

$q_{c p}^{F R, \text { eff }} \leq D_{c p}^{\max }+\left(1-\mathrm{SEL}_{c p}^{F R}\right) \cdot M ; \forall c \in C, p \in P$

$\sum_{c \in C} q_{c p}^{\text {str,eff }}+\sum_{c \in C} q_{c p}^{f r, \text { eff }} \leq \mathrm{CAP}_{p} ; \forall p \in P$

For the tentative calculation of the revenues resulting from the application of the two rates, it is necessary to determine the associated contingents $q_{c p}^{S R, F F}$ as well as $q_{c p}^{F R}$. The model allocates only one of these contingents. The allocated contingents are called the effective contingents $q_{c p} P R$,eff resp. $q_{c p}^{F R \text {,eff }}$ and (25) resp (27). determine their values. An effective contingent has the maximal demand as upper bound (26) as well as (28). Effective contingents quantify the actual resource consumption. The sum of effective contingents allocated to different shippers in period $p$ must not exceed the available capacity in this period (29).

We call the decision model (1)-(29) the stable rate model since it determines a period-invariant rate that is offered without adaptation over the entire planning horizon.

\section{Experimental results}

We set up an artificial freight rate planning scenario and use the associated parameters to state the proposed mixed-integer linear program. After the parameterization is complete, we solve the resulting models using the standard solver software CPLEX and analyze the observed results, namely the rates and contingents, as well as the collected revenues.

\subsection{Scenario description}

A carrier wants to maximize its revenue gained from business with three carriers on one OD-service. Therefore, it wants to determine adequate long-term rates for 26 periods in advance. The carrier estimates monotonically declining DPFs with a maximal rate $r^{\max }(c)$ for their customers (the shippers) and the maximal demand $D_{c p}^{\max }$ for each shipper in each period.

$\operatorname{APF}_{c}(q)=\left(\frac{r^{\max }(c)-0}{0-D_{c p}^{\max }} \cdot q+r^{\max }(c)\right) \cdot F_{v}(q)$ 
$F_{v}(q)= \begin{cases}1, & q=0 \\ F_{v}(q-1) \cdot v^{\frac{q}{10}} & q=1, \ldots, D_{c p}^{\max } \\ 0 & q>D_{c p}^{\max }\end{cases}$

In order to investigate the impacts of differently shaped DPFs, we use the parameterized DPFs given in (30). These DPFs determine the rate $D P F_{c}(q)$ associated with the contingent $q$ allocated for shipper $c$. We use the factor $F_{v}$ (q) to define the price-sensitivity of shipper $c$. This sensitivity mainly depends on the value of the parameter $v$. For shipper $c=1$, we assume $v=0.97$. The resulting DPF is under proportional. For shipper 2 applies $v=1.00$, but shipper $c=3$ deploys $v=1.01$. Fig. 1 prints the resulting three differently-shaped DPFs. The three DPFs induce different rates for a given contingent, but the same rate requires different contingents allocated to the three shippers.

Shipper 1 possesses a willingness-to-pay $r^{\max }(1)=$ $1000 € /$ TEU (maximal demand equals 600 TEU), but shipper 2 pays not more the $r^{\max }(2)=600 €$ for a TEU (max. demand equals $800 \mathrm{TEU}$ ). The third and last shipper is willing to pay at most $r^{\max }(3)=400 €$ for a TEU (max. demand equals 1000 TEU). In all three cases, the number of TEUs to be purchased by one shipper increases if the rate falls.
Fig. 1 Shipper-specific DPFs in the experiments

Fig. 2 Shipper-specific revenue functions and optimal individual rates
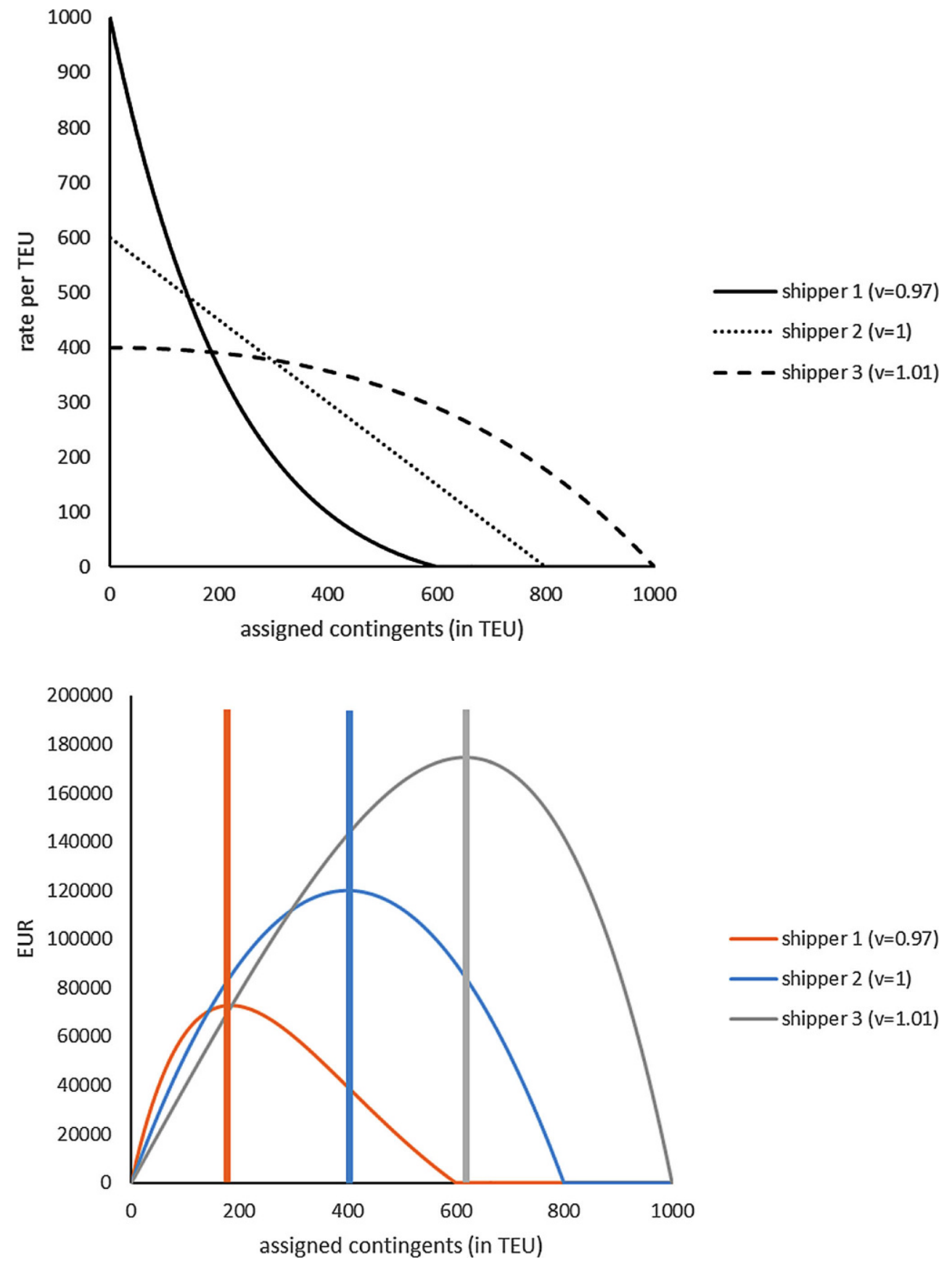
Fig. 2 shows the different revenue functions $q \cdot D P F_{c}(q)$ with different maximum points (marked by the vertical bars). The optimal allocation for shipper 1 is 184TEUs, and the associated freight rate per TEU is $395.86 €$, but shipper 2 maximizes its payments if $400 \mathrm{TEU}$ are sold with a freight rate per TEU of $300 €$. The optimal freight rate for shipper 3 is $280 €$ if the carrier reserves 624 TEUs for this shipper. In order to realize these revenues, the shipper must provide $184 \mathrm{TEUs}+400 \mathrm{~s}$ TEUs $+624 \mathrm{TEUs}=1208 \mathrm{TEUs}$. Over the 26 considered periods, these rates enable the carrier to gain the total revenue sum of 9557 TEUR carrying 31,408 TEU at most.

\subsection{Simulation results}

\subsubsection{Scenario A: stable SR/stable shipper rate}

We use this scenario to validate our proposed pricing model. While we assume that the spot market rate remains stable over the entire planning horizon $\left(S R=S R_{p}(p \in P)\right)$. We investigate changes in the capacity utilization as well as the revenues for the considered vessel service for the values $S R \in\{200 ; 250 ; 300 ; 350 ; 400\}$.

Initially, we deploy the stable rate model. We distinguish two situations. First, the available vessel capacity per period is 2400 TEU ("A-non-scarce"). Second, we assume that only 1210 TEUs are available per period on the vessel service ("A-scarce").

Table 1 contains the determined shipper-specific rates, the assigned contingents, the capacity utilization (CU) as well as the collected total revenue sum (deviation from the $\mathrm{SR}=400 €$-situation). If the market rate SR falls, then the determined fixed rates also decrease. The carrier tries to compensate reduced revenues per TEU by an increase of the accepted TEUs from the carriers in the non-scarce capacity situation (left part of Table 1). We observe a revenue decrease of up to $13 \%$ if the SR is halved from $400 € / T E U$ down to $200 € / T E U$. At the same time, the number of accepted TEUs (sum for all three shippers) is increased by $50 \%$. In the scenario A-scarce (right part of Table 1), the capacity is scarce so that an increase of the assigned contingents is impossible. Here, the carrier tries to keep the rate as high as possible for each carrier until the SR is too low. Consequently, the gained revenues are more affected now by the SR-reduction. Fewer revenues are gained in periods with low SR in the scenario of limited vessel capacity compared to the scenario with sufficient capacity.

\subsubsection{Scenario B: volatile SR/stable shipper rate}

We repeat the experiments above but let the spot market rate vary now with ongoing time. The sequence 240,260 , 280, 320, 360, 380, 390, 390, 360, 340, 340, 320, 320, 300,

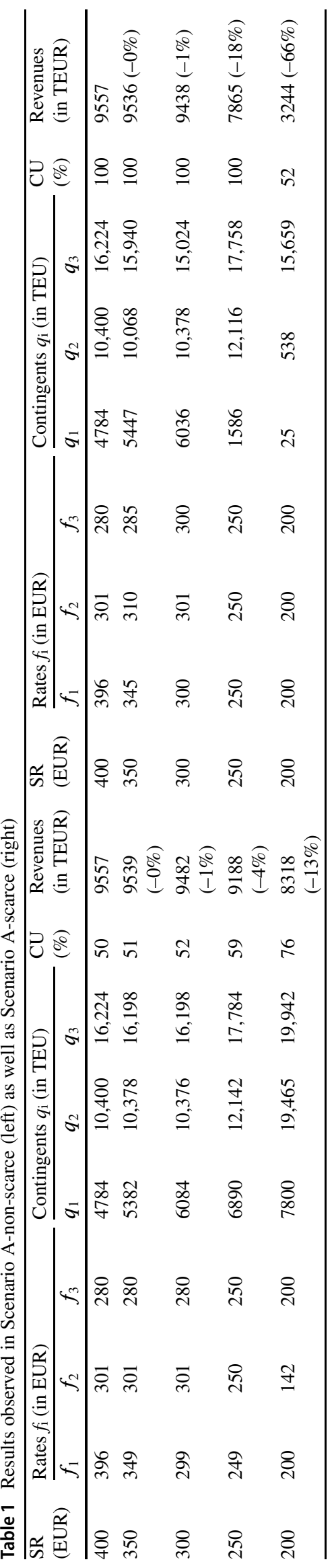


$280,260,260,300,320,340,360,340,300,280,240$ and 220 of spot market rates is used to parameterize the model (1)-(29). Whenever the spot market rate falls below the individually agreed freight rate $f_{c}$ of a shipper, the shipper has the power to overrule the contracted rate, and the corresponding SR of the current period applies. Furthermore, we assume that the shipper-specific $D P F_{c}$ determines the associated number of sold TEUs. The resulting TEU-values for the three shippers are 5939, 10,906, and 16,609 (total sum 33,454$)$. These quantities let the shipper-specific revenue sums become $1,817,520 €, 3,093,740 €, 4,510,500 €$ leading to a total revenue sum of $9,421,760$ TEUR for the carrier. The maximal carrier capacity must be $1526 \mathrm{TEU}$ (in period 26). On average, the capacity utilization rate is $84 \%$, but it varies between 79 and $100 \%$.

Table 2 summarizes the quantitative observations in scenario $B$ for the different vessel capacities. In case that the vessel capacity reduces, the carrier keeps all rates stable but increases the capacity utilization. Only a small revenue loss happens $(-2 \%)$ until the capacity falls to 1300 TEU. As soon as the vessel capacity is exhausted (capacity 1200 TEUs), the carrier starts to adjust the long-term rates. The more we reduce the vessel capacity, the more the long-term rates $f_{1}, f_{2}$, and $f_{3}$ climb. However, the contribution of the revenues from the three shippers is kept more or less stable. However, the distribution of the total vessel capacity to the three shippers is only slightly varied. In some situations, the carrier does not fix a long-term competitive rate ("-") but uses only the SR to serve shipper 1. Finally, for the smallest vessel capacity, no freight rate discrimination is useful anymore, and the revenue sum collapses by up to $40 \%$.

Fig. 3 shows the evolution of the SR (in relation to $S R_{0}$ ) and contingents allocated to the three shippers (also in relation to the initially assigned contingents in period 0). During the first SR-peak between period 3 and period 7, there is a stable distribution of the available capacity to the shippers. As soon as the SR starts to change from period to period, we can observe a contingent adjustment from period to period. Significant and extreme contingent variations occur in both types of SR-changes. During phases of SR-increase as well as phases of SR-decrease, the contingents assigned to the shippers are unstable. This behavior might be problematic since the shippers might demand a stable contingent.

We finally investigate changes in the times when the carrier gains the revenues after we change the available vessel service capacity. The two lines in Fig. 4 demonstrate that the situation is different in a non-scarce (dashed) and in a rare capacity situation (continuous). The lines show for each period the revenue earned in this period divided by the revenue sum earned in the 26 periods after the scaling of the values into the interval $[0 ; 1]$. In periods with low SR, their contribution to the total revenue is significantly less if the capacity is scarce compared to the situation where

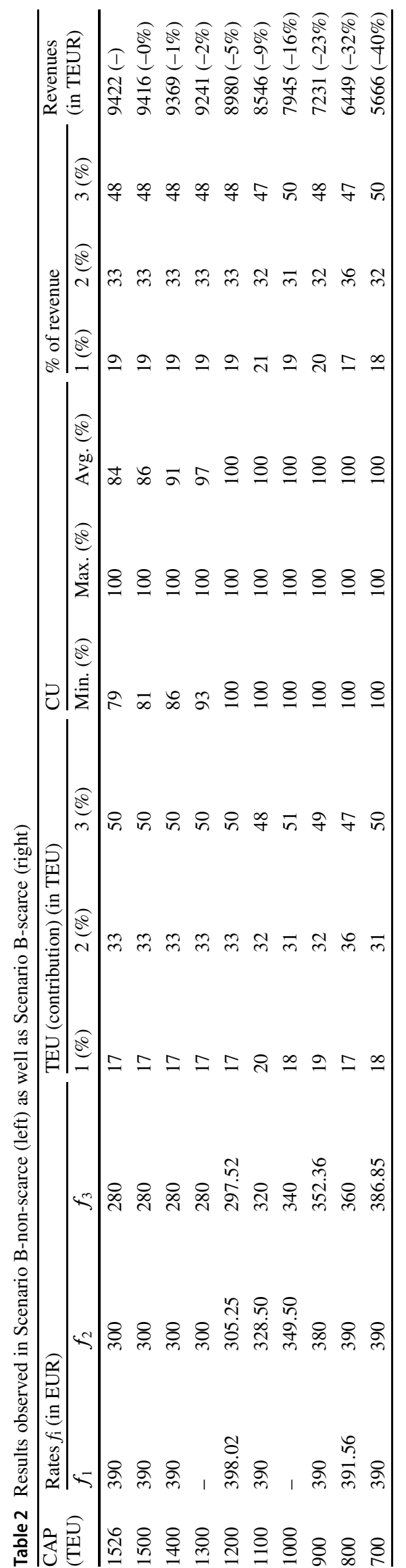


Fig. 3 Evolution of assigned contingents to the carriers
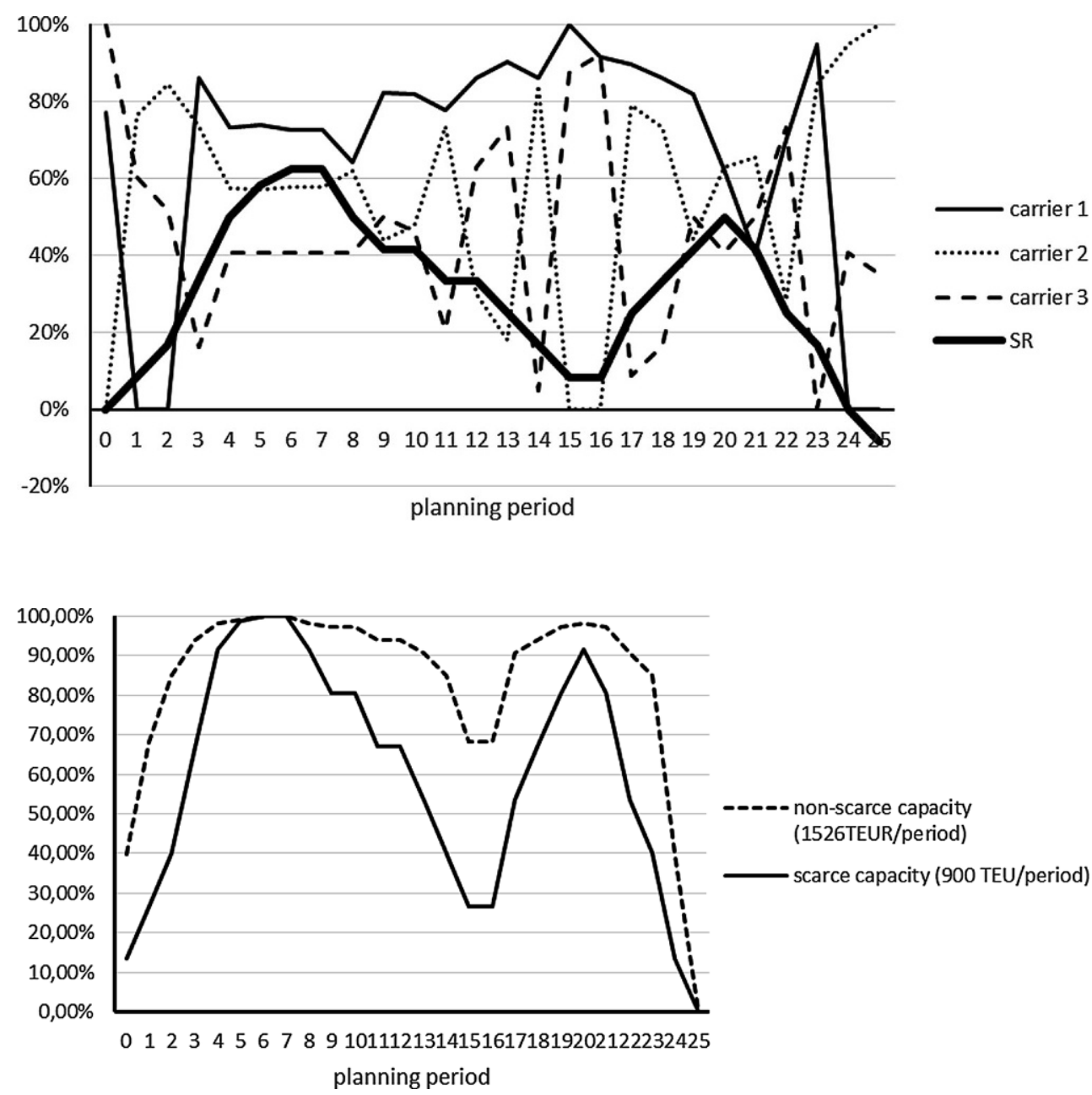

Fig. 4 Distribution of totally gained revenue the capacity is non-scarce. This observation follows from the impossibility to increase the contingents assigned to the shippers, which results in revenue loss.

\section{Summary, conclusions, and outlook}

This article reports the development and validation of a freight rate optimization approach based on mathematical programming. It exploits the functional interdependency between the price of a (service) product and the quantity of the product that can be sold for the price. Solving the proposed model enables a differentiated and shipper-specific rate determination accompanied by the allocation of the transport capacity provided by the carrier for different shippers. The bilateral pricing between carrier and shippers considers market-based reference rates. Herewith, we integrate market-based pricing with demand-based pricing. Computational experiments validated the proposed model for an artificial pricing scenario. An analysis of the achieved results demonstrates that missing overcapacities will lead to reduced revenues in case the spot market prices are too low.

Although the proposed model leads to consistent as well as valid results, further research is necessary to extend the covered decision situation. DPFs should be varied over the periods and coupled with the spot market rates. Instead of considering only one leg in a network, the complete network should be integrated into the model. Finally, different trends in the development of the spot market rates must be studied. In particular, the DPFs should be varied if the market situation changes. Furthermore, it is necessary to integrate the freight determination in a rolling horizon planning re-planning context in order to cope with demand forecast errors.

As already pointed out in the introductory section of this article, the carrier-oriented price optimization is only one side of pricing. In order to adequately integrate the shipper's perspective, it is unconditionally necessary to develop and implement choice models into the here presented rate optimization framework as necessary next research steps. 
Furthermore, it is necessary to investigate how the pricing scheme influences GHG and other emissions in the maritime container shipping industry. As a first step, it is planned to approach this topic by utilizing a qualitative online survey. The results can then be used to approximate the vessel operation related emissions.

Funding Open Access funding provided by Projekt DEAL.

Conflict of interest J. Schönberger declares that he has no competing interests.

Open Access This article is licensed under a Creative Commons Attribution 4.0 International License, which permits use, sharing, adaptation, distribution and reproduction in any medium or format, as long as you give appropriate credit to the original author(s) and the source, provide a link to the Creative Commons licence, and indicate if changes were made. The images or other third party material in this article are included in the article's Creative Commons licence, unless indicated otherwise in a credit line to the material. If material is not included in the article's Creative Commons licence and your intended use is not permitted by statutory regulation or exceeds the permitted use, you will need to obtain permission directly from the copyright holder. To view a copy of this licence, visit http://creativecommons.org/licenses/by/4. $0 /$.

\section{References}

Bertsimas D, Popescu I (2003) Revenue management in a dynamic network environment. Transp Sci 37(3):257-277

Dai J, Ding W, Kleywegt A, Wang X, Zhang Y (2014) Choice Based Revenue Management for Parallel Flights. SSRN Electronic Journal. https://doi.org/10.2139/ssrn.2404193

Doostizadeh M, Ghasemi H (2012) A day-ahead electricity pricing model based on smart metering and demand-side management. Energy 46:221-230

ECSA (2017) Shipping and global trade towards an EU external shipping policy. https://www.ecsa.eu/sites/default/files/publications/ 2017-02-27-ECSA-External-Shipping-Agenda-FINAL.pdf. Accessed 20.05.2020

Edenhofer O, Pichs-Madruga R, Sokona Y, Farahani E, Kadner S, Seyboth K, Adler A, Baum I, Brunner S, Eickemeier P, Kriemann B, Savolainen J, Schlömer S, von Stechow C, Zwickel T, Minx JC
(2014) IPCC, 2014: climate change 2014: mitigation of climate change. Contribution of working group III to the fifth assessment report of the intergovernmental panel on climate change. Cambridge University Press, Cambridge, New York

European Commission (2019) Study on methods and considerations for the determination of greenhouse gas emission reduction for international shipping-final report: short-term measures. Publications Office of the European Union, Luxembourg

Fu L, Kulkani R (2013) Model-based dynamic pricing algorithm for managed lanes. Transp Res Rec 2333(1):74-79

IEA (2019) CO2 emissions from fuel. IEA, Paris, France

IMO (2015) Third IMO greenhouse gas study 2014. international maritime organization, London

IMO (2018) Noteby the International Maritime Organization to the UNFCCC Talanoa Dialogue. https://unfccc.int/sites/default/files/ resource/250_IMO\%20submission_Talanoa\%20Dialogue_April $\% 202018$.pdf. Accessed 20.05.2020

Jugovic A, Komadina N, Hadzic AP (2015) Factors influencing the formation of freight rates on maritime shipping markets. Sci J Marit Res 29:23-29

Kimes SE (2010) Strategic pricing through revenue management In: Enz C (Ed.) The Cornell School of Hotel Administration handbook of applied hospitality strategy. SAGE, Los Angeles, CA, pp 502-513

Sames PC, Köpke M (2012) CO2 emissions of the COntainer world fleet. Procedia 48:1-11

Schubert L (2013) Preisbildung im LKW-Ladungsverkehr. DVV-Media, Hamburg

Temme J (2007) Discrete-Choice-Modelle. In: Albers S et al (ed) Methodik der empirischen Forschung. Gabler, Wiesbaden, p 327

Vulcano G, van Ryzin G, Chaar W (2010) Choice-based revenue management: an empirical study of estimation and optimization. Manuf Serv Oper Manag 12(3):371-392

Walker TR, Adebambo O, Del Aguila Feijoo MC, Elhaimer E, Hossain T, Johnston Edwards S et al (2019) Environmental effects of marine transportation. In: World seas: an environmental evaluation (Second Edition), Academic Press, pp 505-530. https://doi. org/10.1016/B978-0-12-805052-1.00030-9

Wang Y, Meng Q, Du Y (2015a) Liner container seasonal shipping revenue management. Transp Res Part B 82:141-161

Wang Y, Liu Z, Bell M (2015b) Profit-based maritime container assignment models for liner shipping networks. Transp Res Part B 72:59-76

Yin M, Kim KH (2012) Quantity discount pricing for container transportation services by shipping lines. Comput Ind Eng 63:313-322 